\title{
Technology of pedagogical coaching as a basic model of supporting the personal development of students
}

\author{
Marina Valerievna Pisklova ${ }^{11}$ and Marina Ivanovna Bekoeva ${ }^{2}$ \\ ${ }^{1}$ Sechenov First Moscow State Medical University, Institute of Linguistics and Intercultural \\ Communication, Moscow, Russia \\ ${ }^{2}$ North Ossetian State University, Department of Pedagogy, Vladikavkaz, Russia
}

\begin{abstract}
The article substantiates the urgency of the problem of implementing the pedagogical coaching technology as a basic model of support for the personal development of students in the context of modernization of Russian education. Performing value-motivational and personal-semantic functions in the educational process, innovative technologies actualize and develop internal resources of the personality of students, form the necessary competencies that ensure their preparedness to independently solve not only professional tasks, but also various life situations. In modern society, the role of a higher school teacher as a carrier of scientific knowledge is transformed into the role of a coach teacher who focuses the main attention on the development of emotional and cognitive resistance of students to constantly changing conditions; on the formation of the competitiveness of students as future specialists in the modern labor market; on the acquisition of skills to analyze, compare, generalize educational information and apply it in practice; on development of skills for self-education and career growth. In this regard, the purpose of the article is to study the technology of pedagogical coaching in the aspect of new opportunities for developing creative partnerships between all participants in the educational process. The main idea of implementing the technology of pedagogical coaching in higher education is to form students' ability to set constructive goals, apply the most effective methods for solving professional problems, and develop skills of self-organization and self-development. The mechanisms for implementing the technology of pedagogical coaching do not only complement and expand the personal and social components of professional activity, but also make them more meaningful and rational, which allows optimizing their results in practical activity. The authors conclude that pedagogical coaching in the field of education is a necessary innovative technology capable of concentrating the internal resources of a teacher and students on achieving the intended result and can be considered as an effective mechanism for increasing the creative interaction of all participants in the educational process.
\end{abstract}

Keywords: pedagogical coaching technology, personal development of students, self-development, self-realization

\footnotetext{
${ }^{1}$ Corresponding author: mpisklova85@mail.ru
} 


\section{Introduction}

Any transformations taking place in the social, political, economic, educational and other spheres of society and state are correlated with the level of professional competence of specialists in all areas without exception, their individual qualities, value system, life priorities, etc. Therefore, today the higher education system faces an acute problem of developing not only professional competence of students as future specialists, which consists of universal, general professional and professional competencies, but also their coaching skills that contribute to maximum self-development and full self-realization in the chosen profession, development of a creative style of thinking, system integration and self-organization in various life situations.

In the process of supporting personal development of students, some researchers note, it is advisable to rely on a methodological guideline that is significant in modern conditions the organization of teaching and educational process mainly through the lens of the synergetic potential of pedagogical coaching technology $[1,2]$. "In the West, the paradigm of coaching as a special style of learning interaction has developed on the basis of reflection on advanced approaches in the field of mentoring and business consulting. This technology helped people develop, learn new skills and achieve great success in business and management. Currently, the idea of coaching has begun to be implemented in teaching practice in Russia" [3].

Most Russian [4-6] and foreign scholars [7-9] studying the phenomenon pedagogical coaching, consider it as an organizational and functional technology aimed at organizing a personal and confidential learning process; successful solution of current and strategic educational tasks; increasing effectiveness of learning and educational activities, personal development of each student; developing skills in building business projects; optimization of the effectiveness of the educational process as a whole. "Coaching, unlike other technologies, is a personal learning process for two reasons. The first reason why coaching is individualized is that this teaching technology implies the exclusivity of the set of knowledge for each student, the speed of perception of information, the degree of trainability and learning style. The second reason might be acceptability of applying coaching for feedback concerning strengths and weaknesses of a student" [10].

The foregoing suggests that assimilation of mechanisms of self-organization and self-development in order to increase the performance of a person at any age, formation of psychological resistance to changes, to the perception of innovative socio-economic and political transformations are the key to a fruitful organization of professional activity for an employee in any area, as well as maintaining proactive attitude for many years.

\section{$2 \quad$ Methods}

Analyzing pedagogical coaching technology as a universal means of personal development of students as future specialists, their flexible adaptation to highly competitive labor market, we focused on its intellectual-cognitive, personality-oriented, value-motivational and self-regulatory functions.

The intellectual-cognitive function of pedagogical coaching is manifested in the fact that when implementing this technology, the teacher gradually leads students so that they themselves find answers to the questions posed and take responsibility for the reached solutions of creative research tasks, feel satisfaction from the activity itself driven by motivation for achieving success in cognitive and research activities.

The personality-oriented function of pedagogical coaching is characterized by its ability to help students better understand themselves, understand the boundaries of their problem areas, consciously change their personal qualities for the better, learn to solve professional 
tasks in a more balanced and efficient way and to successfully implement them both in their work activity and in life in general.

The value-motivational function of pedagogical coaching, as a constantly developing phenomenon that changes in the process of life, contributes to the genuine motivation of students to work; formation of a value attitude to training, assimilation of all the necessary professional competencies; acquisition of life experience; integration of procedural and discrete characteristics of each one; conscious setting of long-term life goals; changes in the psychological attitudes of students due to which the process of interaction between the teacher and students reaches the subjective and personal level.

The self-regulating function of pedagogical coaching is expressed in the management of self-knowledge, self-development and, accordingly, rational goal-setting. This function is not based on knowledge, experience, competence, or anticipation of the result of coaching, but more on the students' ability to learn for them; select the necessary educational material; be able to independently conduct research; creative actions as criteria for assessing the student's personal development; put in their actions predominantly convincing personal meaning. It is to increase the personal potential of each student and the assimilation of cultural achievements of mankind that the self-regulating function of pedagogical coaching is aimed at.

\section{$3 \quad$ Results}

According to the requirements for the results of assimilation of educational programs presented in the new federal state educational standards of higher education (FSES HE) [11], "professional competencies are formed on the basis of professional standards corresponding to the professional activities of graduates, as well as on the basis of the analysis of requirements for professional competencies imposed on graduates at labor market, generalization of domestic and foreign experience, consultations with leading employers, associations of employers in the industry in which graduates are in demand" (2018).

Considering the rapidly growing demands of the modern labor market for an employee in a highly competitive environment, it should be noted that there is a need for flexibility and adaptability to changes, technological innovations, high-speed global communications, which are becoming more and more tangible over the years. Such technological changes in the education system, as well as the growth of labor market requirements for the model of a specialist, have actualized the problem of implementing pedagogical coaching as the most effective technology for personal development, formation of professional competencies.

Analysis of studies on the indicated problem, their generalization and enrichment with our own conclusions allowed us to develop a three-level model of pedagogical coaching technology [12-14]. We partially implemented this model as a small pilot project at the Department of Pedagogy of the Khetagurov North Ossetian State University (NOSU).

The first level of the model assumes teaching pedagogical coaching to the staff of the department according to the program which included: mastering basic coaching skills, ability to build trusting relationships, listen carefully, be able to ask questions correctly; mastering the technique of implementing coaching contributing to the development of students' creative abilities, self-development, self-regulation, self-study; the ability to set goals and independently strive for their successful achievement. Upon completion of the first level, all teachers noted the effectiveness of this work, assessing their own abilities as a coach teacher.

At the second level of the implementation of the model, the teachers conducted classes already mainly based on the technology of the coaching approach. Many teachers noted that the knowledge gained is not enough for the full and effective implementation of the 
technology, since they have not gained practical experience in this activity. The implementation of such a complex, but at the same time, effective technology presupposes the shaping of a special educational environment that involves both all students of the course and teachers who teach other disciplines to these students.

The third level is designed to train teachers who want to work with this technology. Each teacher has the opportunity to get acquainted with pedagogical coaching technology on the website of the Center for Distance Education of NOSU, or on the website of the Department of Psychology and Pedagogy of NOSU. This level has not yet been implemented, an active preparation for its approbation is still under way. It is planned to implement the third level according to a specially developed program not only for teachers of NOSU, but also for other universities on the grounds of the Center for professional advancement and retraining of personnel of NOSU.

\section{Discussion}

Pedagogical coaching as the leading factor in the personal development and professional becoming of students, a toolkit for intellectual and managerial work, an indicator of human thinking, is a strategically important resource necessary for the further development and continuous improvement of human capital, progressive development of any state. Zinevich and Petrova write in their research, "In accordance with the definition and philosophy of coaching declared by the International Federation of Coaching, professional coaching is a process of providing professional services that helps clients achieve qualitatively new results in their personal and professional lives. The coaching process allows clients to deepen their knowledge, improve efficiency and enhance the quality of life" [15]. Undoubtedly, the value, content, technological modifications of the higher education system require changes in the teachers, their professional competencies, pedagogical position, personal qualities, which should best contribute to the personal development of students as future specialists, to the increase in the productivity and efficiency of the teaching and educational process, and to the improved self-esteem of students.

\section{Conclusion}

Thus, the pedagogical coaching technology in the higher education system, when properly implemented, contributes to: increasing effectiveness of pedagogical activity; psychological support of students both in professional activity and in life in general; correct setting of reasonable and relevant goals; adequate definition of short-term and long-term life goals; developing personal time management skills; increasing level of self-esteem and self-confidence; effective and quick overcoming of unfavorable life and professional situations.

\section{References}

1. E.V. Kostyreva, Bul. “Orley”-KST 4(18), 87-91 (2017)

2. S.Yu. Lavrentiev, D.A. Krylov, Vestnik Mari State Univ. 13(2(34)), 82-188 (2019). https://doi.org/10.30914/2072-6783-2019-13-2-182-188

3. I.A. Efremova, Sci. Investig. Edu. 1(19), 27-30 (2015)

4. E.Yu. Volchegorskaya, M.B. Khabibulina, Baltic J. Human. 9(3(32)), 195-198 (2020). https://doi.org/10.26140/bgz3-2020-0903-0048 
5. Yu.B. Kostrova, O.Yu. Shibarshina, Edu. Resour. Tech. 2(27), 27-32 (2019). https://doi.org/10.21777/2500-2112-2019-2-27-32

6. A.M. Machukha, O.S. Vasilyeva, Mod. Sci.: Curr. Iss. Theory and Pract. Ser.: Knowledge 1, 39-45 (2021). https://doi.org/10.37882/2500-3682.2021.01.09

7. L. Carro, 2016 Update to the European Inventory on Validation of Non-Formal and Informal Learning. Country report. Spain. Accessed on: July 23, 2021. [Online]. Available: https://cumulus.cedefop.europa.eu/files/vetelib/2016/2016_validate_ES.pdf

8. F. Villar, M. Celdran, Europ. J. Ageing 10(2), 135-144 (2013). https://doi.org/10.1007/s10433-012-0257-1

9. P. Werquin, (2010) Recognition of Non-Formal and Informal Learning: Country Practices. Accessed on: July 23, 2021. [Online]. Available: https://www.oecd.org/education/skills-beyond-school/44600408.pdf

10. T.O. Sundukova, G.V. Vanykina, Curr. Iss. Modernity 2(24), 86-90 (2019)

11. FGOS VO $(3++)$ po napravleniyam bakalavriata / Portal Federalnykh gosudarstvennykh obrazovatelnykh standartov vysshego obrazovaniya [FSES HE $(3++)$ for Bachelors / Portal of Federal State Educational Standards of Higher Education]. Accessed on: July 23, 2021. [Online]. Available: http://fgosvo.ru/fgosvo/151/150/24

12. L.V. Bykasova, I.N. Samoilova, Success in Human. 7, 96-100 (2020)

13. J. Dammerer, V. Ziegler, S. Bartonek, Yaroslavl Pedag. Bul. 1(106), 56-69 (2019). https://doi.org/10.24411/1813-145X-2019-10278

14. O.Yu. Korovina, I.V. Litvin, Source, 2, 47-48 (2018)

15. O.V. Zinevich, E.D. Petrova, Sib. Pedag. J. 8, 172-177 (2012) 